\title{
Design methods of urban and regional space utilizing wheelchair probe information
}

\author{
Empirical Study on Accessibility of Shinjuku Station Transfer Using \\ Barrier Free Map "WheeLog!"
}

[ Yuriko Oda, Youichi Oda, Setsuko Kanai, Kosuke Sato, Zong Shichun, Hirotomo Ohuchi ]

\begin{abstract}
This project was co-created with wheelchair users worldwide who posted their experiences and ideas on a map application, and provided details of suitable alternative wheelchair routes. We have proposed these measurement methods and constructed an evaluation model. We believe these are useful as reference for facility development, analysis, and evaluation of future cities and regional spaces.
\end{abstract}

Keywords- Barrier-free, Wheelchair, Post-type, Smartphone, WheeLog!

\section{Introduction}

This project was co-created with wheelchair users worldwide who posted their experiences and ideas on a map application, and by collecting their probe information and details about unevenness of route surface using the GPS and acceleration sensor on their Smartphones. For this study, we conducted research using "WheeLog!," a user-contributed barrier-free map smartphone application created by the authors (Fig.1).

There is no standard for transfer between different railway operators in Japan. The nation calls for municipalities throughout the country to create basic concepts for barrier-free design, including not only individual facilities such as stations but also peripheral areas. In the terminal at Shinjuku Station, development has been progressing in stages because, in addition to cost and structural problems, the management areas of each business enterprise at the terminal station with transfers between different railroads are complicated without consultation, delaying the elimination of barriers to wheel-chair use. The barrier free law establishes criteria relating to the elimination of stairs on the station premises, but excludes transfer routes.

Yuriko Oda, Youichi Oda,

NPO PADM

Japan

Setsuko Kanai,

NIKKEN SEKKEI Ltd.

Europe

Kosuke Sato, Zong Shichun, Hirotomo Ohuchi,

Grad. School of Industrial Technology, Nihon Univ.

Japan
Also, by taking advantage of the ubiquity of smartphones all over the world for collecting barrier-free information, this study has aimed to accumulate information on every location and to make it possible to search all barrier-free information on Earth. Since various sensors are built into smartphones, it is possible to obtain various information simply by attaching a smartphone to a wheelchair to investigate the establishment of facilities and other places, including accommodation facilities, tourist facilities, hospitals, and athletic facilities. "WheeLog!" logs the wheelchair route log on a map using Google Maps. The more a wheelchair user uses a route, the deeper its color on the map. Wheelchair users can refer to the information and contribute to the expansion of information. Parking, step information, the presence of elevators, etc. can also be posted, and some data specifications can be modified, excluding data on contributors. We received the Grand Prix at the "Google Impact Challenge" in 2015, and began offering the application to the general public on May 28, 2017. Although many types of barrier-free maps and information sites of the same type are visible, they can be generated anywhere without being bound by administrative units or regional areas, and few are collected and updated with the latest data in real time. Furthermore, it is the only application that can log wheelchair users' routes internationally.

This study, promoted by the non-profit organization PADM, utilized barrier-free information on areas visited by wheelchair users all over the world to establish a simple evaluation method that can be utilized mainly by elderly people and people with disabilities using wheelchairs. Based on the data obtained from the "barrier-free map created by everyone" in the user co-creation project, indicators of mobility (accessibility) were extracted and analysis and

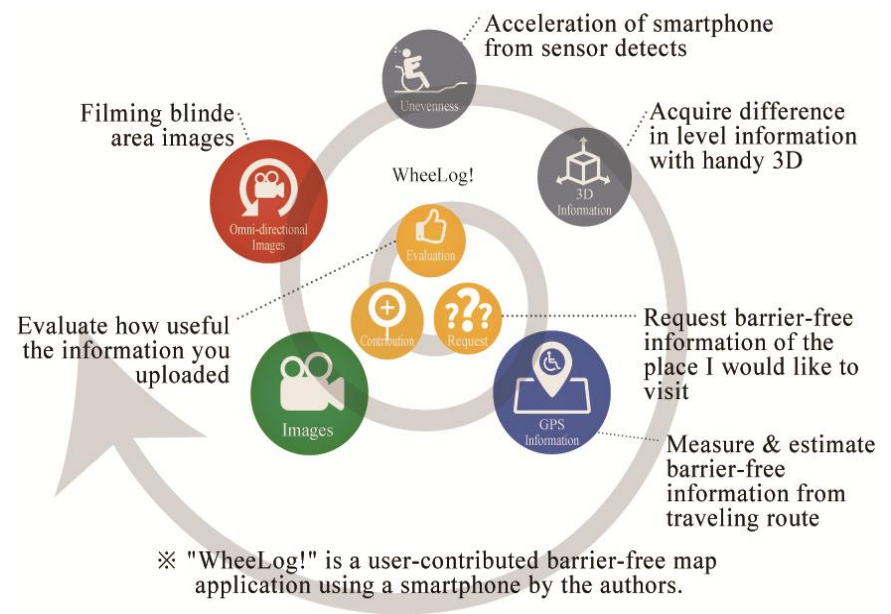

Figure. 1 Overview of "WheeLog!" 
discussion were carried out using an evaluation-calculation model. We conducted an empirical study on wheelchair accessibility of Shinjuku Station transfers using a barrierfree map created with "WheeLog!" (Fig. 2).

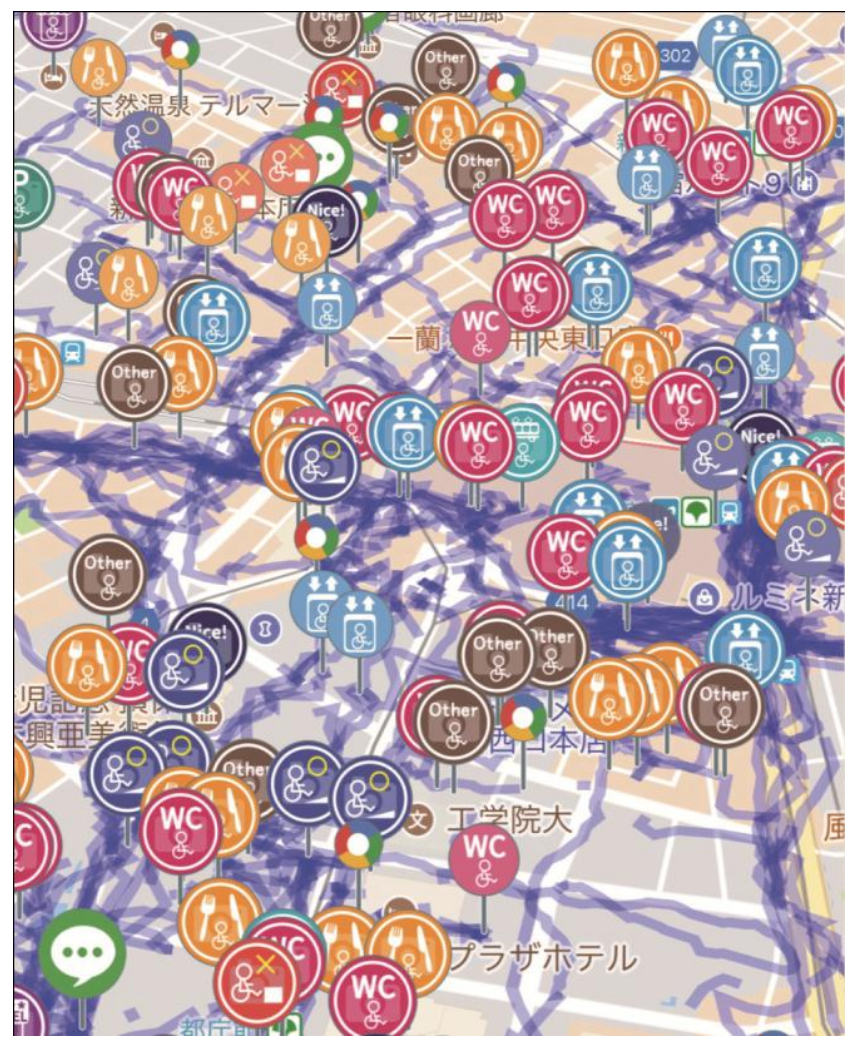

Figure.2 "WheeLog!" display screen (Shinjuku area)
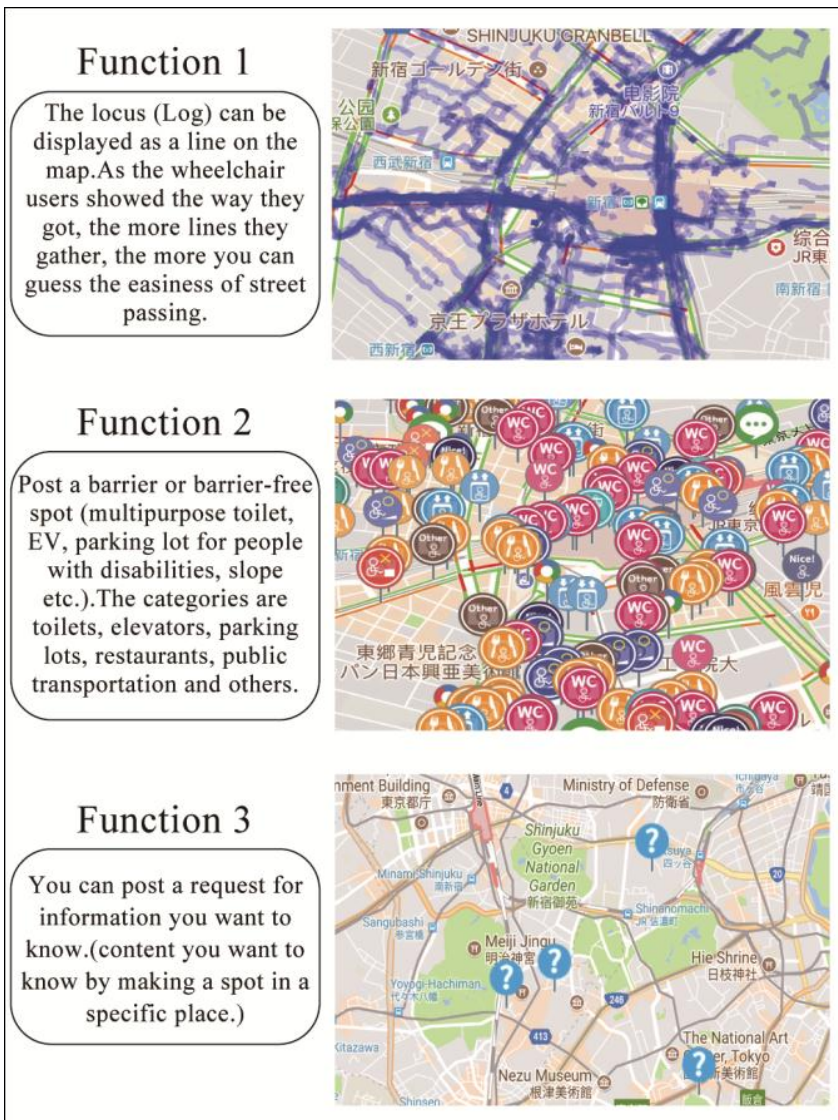

Figure. 3 Three Main Functions of "WheeLog!"

\section{Characteristic and Function of "WheeLog!" (Fig.3)}

\section{A. Convenience}

By searching barrier-free information in advance, users can find their optimal route. In addition, the application not only recommends the best route, but also provides details of suitable alternative routes, so that a wheelchair user can select the route that is most suitable for him or her, depending on his or her disability.

\section{B. Reliability}

By implementing the evaluation function with posts such as "I want to help people," the latest high-quality information can be circulated. Furthermore, to evaluate the usefulness of the updated information, questionnaires are provided in each category, and the contributor and users who are using the application can provide feedback on the degree of accessibility by rating it either "Good" or "Bad."

\section{Communication}

Through continuous operation, it is more possible to locate an optimal route than before in the same length of time. Also, as an incentive to encourage information sharing among users, the application tallies up the evaluations and announces rankings for the users who provide feedback. The top reviewers are gifted prizes by sponsors. In addition, the status of a user increases depending on factors such as the number of posts they have written in the application. It is believed that interaction among users, via means such as comments from other users, likes, and shares on a post, will motivate many users to post relevant information.

\section{Accuracy}

In addition, based on distance data, accessibility indicators are extracted and the latest information necessary for renovation and infrastructure development are collected, not only for people with disabilities, but also for facility managers and administrative officials. Specifically, the quality and accuracy of the shared information cannot be guaranteed by an administrator, because it is posted by private individuals.

However, if the location and contents of posted information are wrong, a mechanism whereby users can report such errors has been incorporated. This mechanism allows administrators and users to share and modify information easily.

\section{E. Diversity}

Furthermore, as the ripple effect continues, the application can be expected to be useful to elderly people, pregnant women, parents using strollers, and so on.

\section{Project Outline}

This project collected barrier-free information by maximizing the capabilities of smartphones, because everyone in the world is beginning to own a smartphone. Since many sensors are built into smartphones, it is possible 
to obtain various kinds of information just by attaching one to a wheelchair. The final goal is to accumulate information from all places and make all barrier-free information on Earth searchable. The information indicates where a wheelchair can pass through based on the traveling history obtained from GPS information, and the acceleration sensor can acquire information on the unevenness of the route surface. By combining images together, one can get information that one cannot understand with just photos. Also, omnidirectional images allow one to check in advance where blind spots are likely when running a wheelchair (Fig. 4). In the near future, tablets will be equipped with $3 \mathrm{D}$ measurement functions like the Google Tango Project, which will make possible wheelchair route simulations from 3D measurement spatial information.
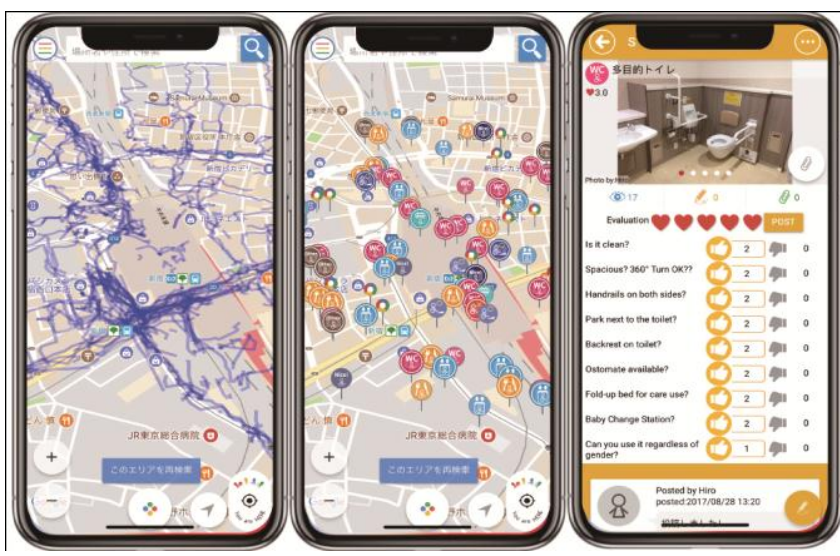

Figure.4 Actual Search Screen of "WheeLog!"

\section{Investigation Area(Fig.5,6)}

As a survey of accessibility during transit between ticket gates, we set Shinjuku Station as the research location. Shinjuku Station is the main train station in the Shinjuku ward of Tokyo. There are ten train and subway routes run by five railway (subway) companies, and the station has 36 platforms and 200 exits. It has an underground arcade, an aboveground arcade, and numerous hallways. Serving as the main connecting hub for rail traffic on inter-city rail, commuter rail, and subway lines, the station has been used by an average of 3.64 million people per day. Therefore, the Guinness World Records recognized Shinjuku Station as the world's busiest station in 2011. This study aimed to collect wheelchair route history by utilizing various sensors in smartphones and for the operation and testing of the barrierfree map application "WheeLog!" (Fig. 7, Table 1, 2).

TABLE I. NUMBER OF PEOPLE BOARDING (DAILY AVERAGE)(2017)

\begin{tabular}{|c|c|c|c|}
\hline Line Name & Commuter ticket & Ordinary ticket & Total \\
\hline 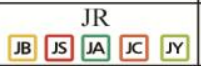 & 408,329 & 360,977 & 769,307 \\
\hline Marunouchi Line & 63,086 & 52,049 & 115,135 \\
\hline $\begin{array}{c}\text { Toei Shinjuku Line } \\
\text { (s) }\end{array}$ & 89,049 & 56,954 & 146,002 \\
\hline $\begin{array}{c}\text { Toei Oedo Line } \\
\text { (e) }\end{array}$ & 37,218 & 30,784 & 68,002 \\
\hline 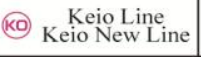 & 248,356 & 135,871 & 384,227 \\
\hline @ $\begin{array}{c}\text { Odakyu } \\
\text { Odawara Line }\end{array}$ & 152,361 & 101,894 & 254,255 \\
\hline
\end{tabular}

From Heisei 29 (2017) Shinjuku Ward Overview (Administrative documents)

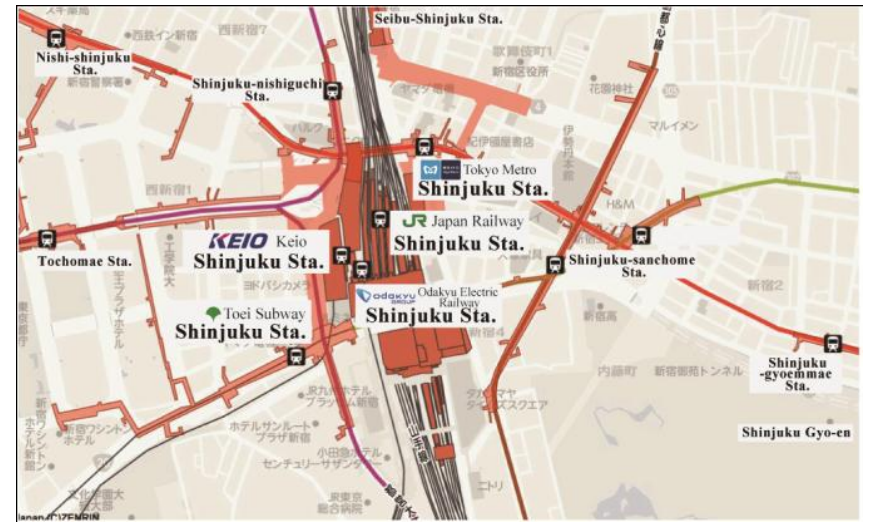

Figure.5 Investigation Area (Station)

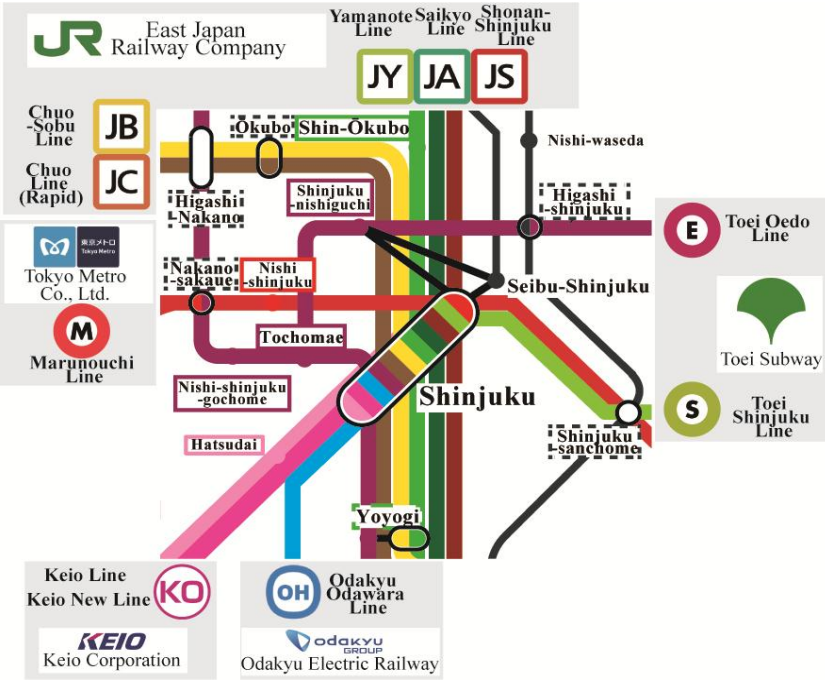

Figure.6 Traffic route Map (Shinjuku sta.)

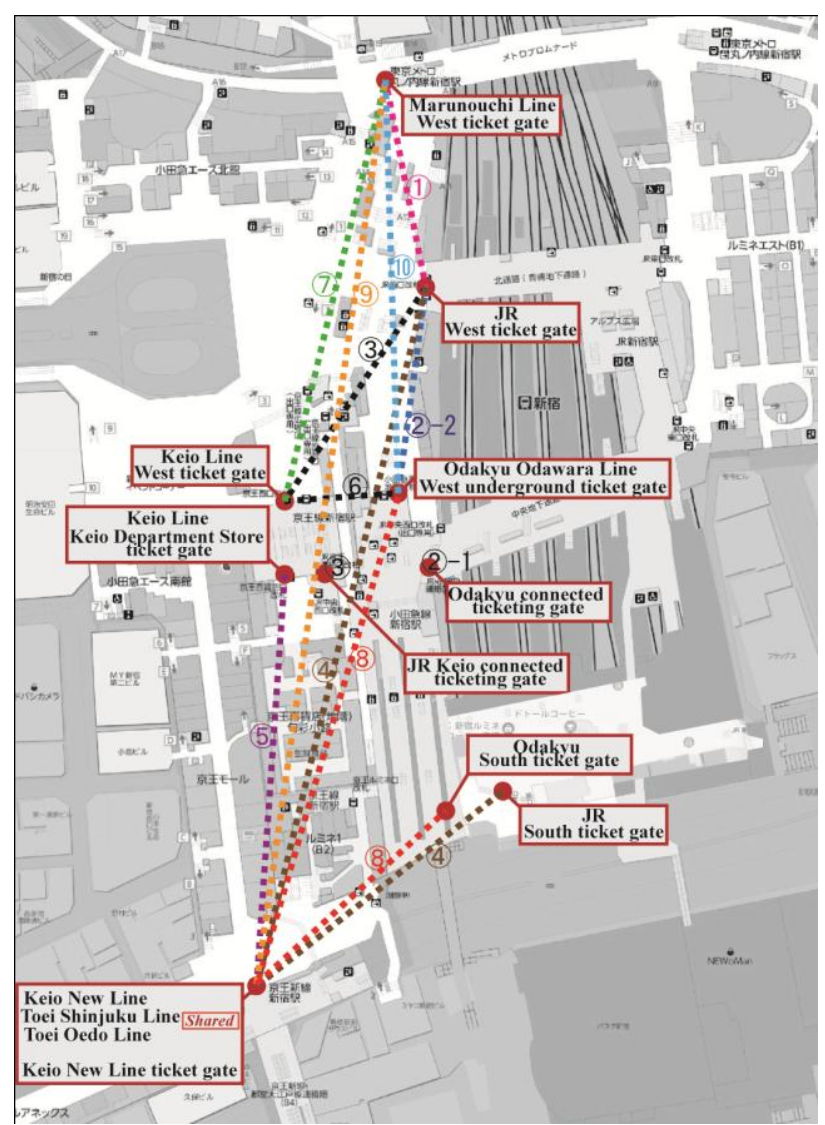

Figure.7 Survey route in the real map (Shinjuku sta.) 
Proc. of The Seventh International Conference on Advances in Computing, Electronics and Communication - ACEC 2018 Copyright (C) Institute of Research Engineers and Doctors, USA. All rights reserved.

ISBN: 978-1-63248-157-3 doi: 10.15224/978-1-63248-157-3-03

TABLE II. VERVIEW OF INVESTIGATION AREA (SHINJUKU STA.)

\begin{tabular}{|c|c|c|c|c|c|}
\hline \multicolumn{6}{|c|}{ Shinjuku Sta. (Outside the gate) } \\
\hline \multirow{2}{*}{ Number } & \multicolumn{3}{|c|}{ Measurement Section } & \multirow{2}{*}{\multicolumn{2}{|c|}{ Moving Method }} \\
\hline & & Line & Ticket gate & & \\
\hline \multirow{2}{*}{ (1) } & \multirow{2}{*}{\multicolumn{2}{|c|}{$\begin{array}{|lc|}\text { J } & \text { JR } \\
\text { (4) } & \text { Marunouchi Line } \\
\end{array}$}} & \multirow{2}{*}{$\begin{array}{c}\text { West } \\
\mathfrak{3} \\
\text { West }\end{array}$} & General & Stairs \\
\hline & & & & Wheelchair user & ELV \\
\hline \multirow{3}{*}{ (2) } & & \multirow{3}{*}{$\begin{array}{c}\text { JR } \\
\{ \\
\text { Odakyu } \\
\text { Odwara Line }\end{array}$} & \multirow{2}{*}{$\begin{array}{c}2-1 \\
\text { Odakyu connected } \\
\text { ticketing gate }\end{array}$} & General & Directly connecting two stations \\
\hline & & & & Wheelchair user & $\begin{array}{l}\text { ELV (Only 7/8th platform) } \\
\text { Directly connecting two stations }\end{array}$ \\
\hline & & & $\begin{array}{|cc|}\text { 2)-2 } & \text { West } \\
\text { West underground }\end{array}$ & Wheelchair user & $\begin{array}{c}\text { Wheelchair user from } \\
\text { 1-6th and 9-16th platforms }\end{array}$ \\
\hline \multirow{2}{*}{ (3) } & \multirow{2}{*}{\multicolumn{2}{|c|}{$\begin{array}{|cc|}\text { R } & \text { JR } \\
\text { (10) } & \text { Keio Line } \\
\end{array}$}} & $\begin{array}{l}\text { JR Keio connected } \\
\text { ticketing gate }\end{array}$ & General & Directly connecting two stations \\
\hline & & & West $\Leftrightarrow$ West & Wheelchair user & Slope \\
\hline \multirow{2}{*}{ (4) } & \multirow{2}{*}{\multicolumn{2}{|c|}{$\begin{array}{|lc|}\text { J } & \text { JR } \\
\text { (ख) } & \text { Keio New Line } \\
\text { (5) } & \text { Toei Shinjuku Line } \\
\text { (3) } & \text { Toei Oedo Line } \\
\end{array}$}} & $\begin{array}{c}\text { South } \\
3 \\
\text { Keio New Line } \\
\text { ticketing gate }\end{array}$ & General & $\begin{array}{c}\text { Stairs (Transit } 2 \text { times) } \\
\text { Escalator (Transit } 2 \text { times) }\end{array}$ \\
\hline & & & $\begin{array}{c}\text { West } \\
\text { Bew Line } \\
\text { Keio New Lice } \\
\text { ticketing gate }\end{array}$ & Wheelchair user & - \\
\hline \multirow{2}{*}{ (5) } & \multirow{2}{*}{\multicolumn{2}{|c|}{$\begin{array}{|cc|}\text { (6) } & \text { Keio Line } \\
\text { \& } \\
\text { «0 } & \text { Keio New Line } \\
\text { (5) } & \text { Toei Shinjuku Line } \\
\text { () } & \text { Toei Oedo Line } \\
\end{array}$}} & \multirow{2}{*}{$\begin{array}{l}\text { Keio Department } \\
\text { Store Gate } \\
\checkmark \\
\text { Keio New Line } \\
\text { ticketing gate }\end{array}$} & General & - \\
\hline & & & & Wheelchair user & - \\
\hline \multirow{2}{*}{ (6) } & \multirow{2}{*}{\multicolumn{2}{|c|}{$\begin{array}{cc}\text { KO } & \text { Keio Line } \\
\text { Odaky } \\
\text { Odakara Line }\end{array}$}} & \multirow{2}{*}{$\begin{array}{c}\text { West } \\
8 \\
\text { West underground }\end{array}$} & General & Stairs \\
\hline & & & & Wheelchair user & Slope \\
\hline \multirow{2}{*}{ (7) } & \multirow{2}{*}{\multicolumn{2}{|c|}{\begin{tabular}{|c|c|} 
(10) & Keio Line \\
(4) Marunouchi Line
\end{tabular}}} & \multirow{2}{*}{$\begin{array}{c}\text { West } \\
\vdots \\
\text { West }\end{array}$} & General & Stairs (Transit 2 times) \\
\hline & & & & Wheelchair user & ELV, Slope \\
\hline \multirow[b]{2}{*}{ (8) } & \multirow{2}{*}{\multicolumn{2}{|c|}{\begin{tabular}{|cc|} 
(k0) & Keio New Line \\
(5) & Toei Shinjuku Line \\
() & Toei Oedo Line \\
\cline { 2 - 2 } & Odaky \\
@ & Odawara Line \\
\end{tabular}}} & \multirow{2}{*}{$\begin{array}{c}\begin{array}{c}\text { Keio New Line } \\
\text { ticketing gate } \\
\text { South }\end{array} \\
\text { Keio New Line } \\
\text { ticketing gate } \\
\text { Wo } \\
\text { West underground } \\
\end{array}$} & General & $\begin{array}{l}\text { Stairs (Transit } 2 \text { times) } \\
\text { Escalator (Transit } 2 \text { times) }\end{array}$ \\
\hline & & & & Wheelchair user & - \\
\hline \multirow{2}{*}{ (9) } & \multirow{2}{*}{\multicolumn{2}{|c|}{\begin{tabular}{|l|} 
(60) Keio New Line \\
(5) Toei Shinjuku Line \\
() Toei Oedo Line \\
(4) Marunouchi Line
\end{tabular}}} & \multirow{2}{*}{$\begin{array}{c}\text { Keio New Line } \\
\text { ticketing gate } \\
0 \\
\text { West }\end{array}$} & General & Stairs \\
\hline & & & & Wheelchair user & ELV \\
\hline \multirow{2}{*}{ (10) } & \multirow{2}{*}{\multicolumn{2}{|c|}{$\begin{array}{c}\text { @) } \begin{array}{c}\text { Odakyu } \\
\text { Odawara Line } \\
\Re \\
\text { (4) Marunouchi Line }\end{array} \\
\end{array}$}} & \multirow{2}{*}{$\begin{array}{c}\text { West underground } \\
\$ \\
\text { West }\end{array}$} & General & Stairs \\
\hline & & & & Wheelchair user & ELV \\
\hline
\end{tabular}

\section{v. Analysis by Evaluation Method Model}

In this study, we measured the shortest distance (straight distance / general flow line / flow line by wheelchair user) between ticket gates in Shinjuku Station, and calculated the overlapping distance between the general flow line and the movement line of people with disabilities as the possibility for wheelchair users to use the general flow line.

As a result, the accessibility proposed in this paper is based on horizontal movement distance from the measurable

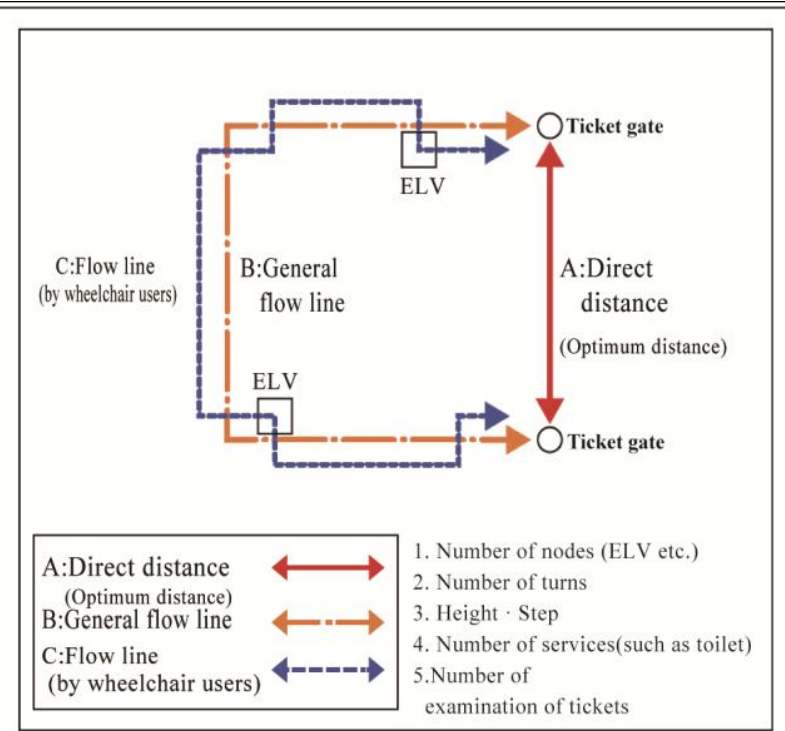

Model route for evaluation calculation

The distance of the shortest distance of a straight line distance (A) - General flow line distance from the origin of the ticket gate to other agencies ticket gate (B) disabilities flow line and $(\mathrm{C})$.

It is possible to evaluate not only the handicapped person but also the preparation level of the general flow line.

The accessibility proposed here is constituted by the distance of horizontal movement from a starting point that can be measured from the barrier-free map to the destination, as shown by the following expression.

$\alpha:$ Accessibility $=$

$\mathrm{A}:$ Direct distance/B:The shortest distance of the general flow line

$\beta:$ Accessibility of wheelchair users $=$

A:Direct distance/C:Flow line (by wheelchair users)

$\gamma:$ Load factor of general flow line $=$

A:direct distance/(A:Direct distance+B:The shortest distance of the general flow line)

$\omega:$ Load factor of wheelchair users $=C$ :Mileage by wheelchair/ ( B : The shortest distance of the general flow line $+\mathrm{C}$ : Mileage by wheelchair)

$\sigma:$ Possibility of accompanying $=\mathrm{B}:$ The shortest distance of the general flow line/C:Mileage by wheelchair

\section{Figure.8 Evaluation method}

starting point (ticket gate) to the destination (ticket gate of another organization) by the barrier free map (WheeLog!), which we analyze and discuss using the evaluation calculation model shown in the figures (Fig. 8, 9).

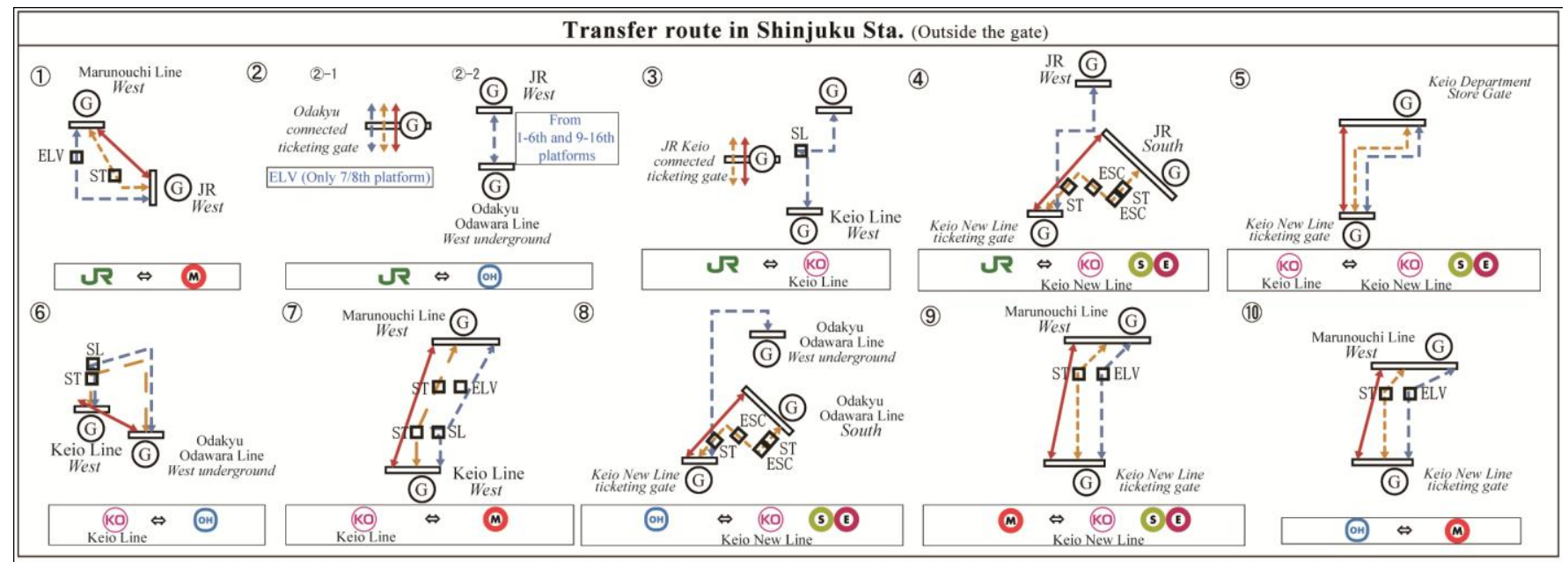

Figure.9 Calculation route of the evaluation model 
Proc. of The Seventh International Conference on Advances in Computing, Electronics and Communication - ACEC 2018 Copyright (C) Institute of Research Engineers and Doctors, USA. All rights reserved.

ISBN: 978-1-63248-157-3 doi: 10.15224/978-1-63248-157-3-03

TABLE III

DISTANCE DATA OF MEASURED VALUE OF SHINJUKU STATION AND ACCESSIBILITY

\begin{tabular}{|c|c|c|c|c|c|c|c|c|}
\hline Number & \begin{tabular}{|l|}
$\mathrm{A}$ \\
Direct distance
\end{tabular} & $\begin{array}{l}\text { B } \\
\text { General flow } \\
\text { line } \\
\end{array}$ & $\begin{array}{c}\mathrm{C}_{\text {Flow line }} \\
\text { (by wheelchair } \\
\text { users) }\end{array}$ & $\begin{array}{l}\alpha=\mathrm{A} / \mathrm{B} \\
\text { Accessibility }\end{array}$ & $\begin{array}{c}\beta=\mathrm{A} / \mathrm{C} \\
\text { Accessibility } \\
\text { (by wheelchair } \\
\text { users) }\end{array}$ & $\begin{array}{c}\gamma=\mathrm{A} /(\mathrm{A}+\mathrm{B}) \\
\text { Load factor of } \\
\text { general flow line }\end{array}$ & \begin{tabular}{|c|}
$\omega=\mathrm{C} /(\mathrm{B}+\mathrm{C})$ \\
Load factor of \\
wheelchair users
\end{tabular} & $\begin{array}{c}\sigma=\mathrm{B} / \mathrm{C} \\
\begin{array}{c}\text { Possibility of } \\
\text { accompanying }\end{array}\end{array}$ \\
\hline (3) & $0 \mathrm{~m}$ & $0 \mathrm{~m}$ & $161.35 \mathrm{~m}$ & $100.00 \%$ & $0 \%$ & $0 \%$ & $100 \%$ & $0 \%$ \\
\hline (2) -2 & $0 \mathrm{~m}$ & $0 \mathrm{~m}$ & $96.60 \mathrm{~m}$ & $100.00 \%$ & $0 \%$ & $0 \%$ & $100 \%$ & $0 \%$ \\
\hline (4) & $134.70 \mathrm{~m}$ & $159.55 \mathrm{~m}$ & $354.80 \mathrm{~m}$ & $84.42 \%$ & $37.97 \%$ & $45.78 \%$ & $68.98 \%$ & $44.97 \%$ \\
\hline$(8)$ & $120.80 \mathrm{~m}$ & $144.55 \mathrm{~m}$ & $237.40 \mathrm{~m}$ & $83.57 \%$ & $50.88 \%$ & $45.52 \%$ & $62.15 \%$ & $60.89 \%$ \\
\hline (1) & $85.20 \mathrm{~m}$ & $92.10 \mathrm{~m}$ & $126.45 \mathrm{~m}$ & $92.51 \%$ & $67.38 \%$ & $48.05 \%$ & $57.86 \%$ & $72.84 \%$ \\
\hline (6) & $33.00 \mathrm{~m}$ & $144.75 \mathrm{~m}$ & $180.15 \mathrm{~m}$ & $22.80 \%$ & $18.32 \%$ & $18.57 \%$ & $55.45 \%$ & $80.35 \%$ \\
\hline (7) & $191.05 \mathrm{~m}$ & $198.25 \mathrm{~m}$ & $232.05 \mathrm{~m}$ & $96.37 \%$ & $82.33 \%$ & $49.08 \%$ & $53.93 \%$ & $85.43 \%$ \\
\hline (10) & $180.85 \mathrm{~m}$ & $186.15 \mathrm{~m}$ & $210.50 \mathrm{~m}$ & $97.15 \%$ & $85.91 \%$ & $49.28 \%$ & $53.07 \%$ & $88.43 \%$ \\
\hline (5) & $181.50 \mathrm{~m}$ & $205.40 \mathrm{~m}$ & $206.60 \mathrm{~m}$ & $88.36 \%$ & $87.85 \%$ & $46.91 \%$ & $50.15 \%$ & $99.42 \%$ \\
\hline (9) & $403.00 \mathrm{~m}$ & $424.40 \mathrm{~m}$ & $426.40 \mathrm{~m}$ & $94.96 \%$ & $94.51 \%$ & $48.71 \%$ & $50.12 \%$ & $99.53 \%$ \\
\hline (2) -1 & $0 \mathrm{~m}$ & $0 \mathrm{~m}$ & $0 m$ & $100.00 \%$ & $100.00 \%$ & $0 \%$ & $0 \%$ & $100.00 \%$ \\
\hline
\end{tabular}

\section{vi. Conclusion}

The measured distance data indicates an index necessary for evaluating mobility (accessibility). In addition, the evaluation model compares the load factor of the general flow line, the load factor of the wheelchair user, and the rate of wheelchair users accompanying the general flow line (Fig. 10, Table 3)

- Compared with the general flow line, the load rate of the flow line for wheelchair users tended to be high.

- Regarding accessibility concerning movement between ticket gates, when the possibility of combining the general flow line and the flow line of wheelchair users increased, the load factor of wheelchair users tended to decrease.

- (3) and (2)-2 in Table 3 are directly transferable on the station yard. However, it is impossible to pass through the barrier by wheelchair, so the travel distance of the wheelchair user is long, and the load factor is high. The flow line, in this case, makes it possible to markedly increase accessibility by eliminating the barrier.

However, in this data, the result concerns planar distance, not the movement of height. In order to adequately secure the freedom of movement specified by the Barrier Free Law, since it is indispensable to grasp data on time taken for the complete movement, it is necessary to move elevators and the like or to wait for movement assistant devices. We believe that future policy will be to establish a method for measuring accessibility, including inclusion of a planned methodology.

As mentioned above, results from West Asian countries have already been posted. Strengthening the contents of the application by user request will promote future development.

Based on the data obtained above, indexes necessary for evaluating mobility (accessibility) were extracted. We have proposed these measurement methods and constructed an evaluation model. We believe these are useful as reference values for facility development, analysis, and evaluation in future cities and regional spaces.

We have already posted results in Asia, Europe, and the United States, and we plan to further expand effects by

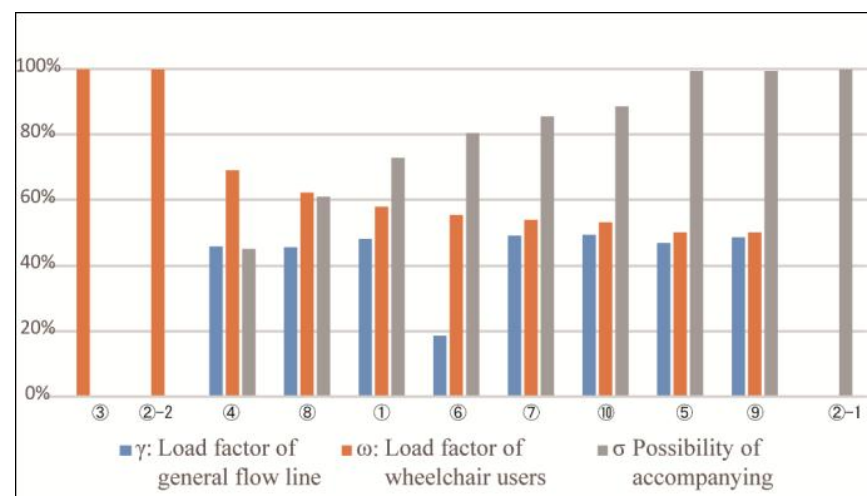

Figure.10 Graph of accessibility (General and Wheelchair Users)

strengthening content based on user requests, further promoting development.

\section{Annotation}

[1] Google Impact Challenge: The Google Impact Challenge is a program to support non-profit organizations that address social problems by utilizing various technologies. Google has held this program in India, Brazil, UK, USA, and Australia, and held in Japan in November 2014. The proposal by the NPO PADM, "'WheeLog!' made by everyone" was chosen for the grand prize

[2] Zero Project Innovative Practice 2018 on Accessibility: We received an award from Zero Project (Vienna). Subject: Connecting wheelchairaccessible maps with GPS tracking.

\section{References}

[1] Humito Ito, Yuriko Oda, Youichi Oda and Yujiro Hayashi :"Proposal of barrier-free map automatic generation method by the sensor group of smartphone" The Institute of Electrics, Information and Communication Engineers Symposium of Human Communication Group, 2015. 12

[2] Sato Hiroyuki, Yoshitaka Aoyama, Dai Nakagawa, Ryoji Matsunaka and Hiroaki Shirayagi "A Study on Factor Analysis of the Transfer Resistance and Estimating the Benefit of the Reducing Project at Terminal" Proceedings of Instructure Planning and Management, Vol. 19, No.4, pp. 803-812, 2002. 10.

[3] Hideki Takayanagi, Tomonori Sano and Hitoshi Watanabe"The Visualization of Pedestrian Flow Efficiency with Interfering Area Model'Lecture of The Visualization Society of Japan, Vol.20, Suppl. No. 2, pp. 57-60, 2000.

[4] "Transport and Tourism,Cost-benefit Analysis Manual" the Ministry of Land, Infrastructure, 2003. 8.

[5] Hironori Kato, Jun Shikai, Jun Hayashi and Haruo Ishida "Socioeconomic Evaluation Model for Project of Improving Transfer at Urban Railway Station” Institute For Transport Policy Studies Vol. 3, No. 2, pp. 9-20, 2000. 
Proc. of The Seventh International Conference on Advances in Computing, Electronics and Communication - ACEC 2018 Copyright (C) Institute of Research Engineers and Doctors, USA. All rights reserved.

ISBN: 978-1-63248-157-3 doi: 10.15224/978-1-63248-157-3-03

[6] "Station Square plan guidelines" Japan Transportation Planning Association, Gihoudou Syuppan, 1997. 7.

About Author (s):

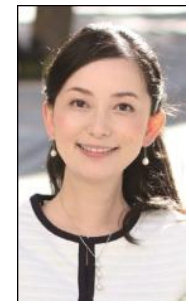

Yuriko Oda was born in Chiba, Japan in 1980. She received Bachelor of Economics from Soka University, Tokyo, Japan in 2003. She is currently president of NonProfit Organization PADM (Patients Association for Distal Myopathies). Application (WheeLog!) inventor.

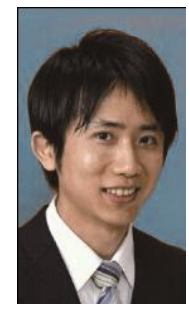

Youichi Oda was born in Nagasaki, Japan in 1980. He received Doctor of Jurisprudence degree from Surugadai University, Saitama, Japan in 2008. He is currently a staff of Non-Profit Organization PADM (Patients Association for Distal Myopathies).

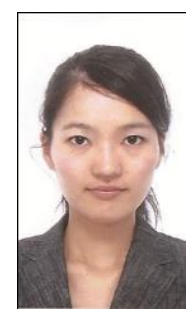

Setsuko Kanai was born in Chiba, Japan in 1983. She received Bachelor of arts degree in education from Soka University, Tokyo, Japan in 2007, and received Bachelor of fine arts degree from Kyoto University of Art and Design, Kyoto, Japan in 2012. She has obtained Tricontinental Master's Degree in Integrated Architectural Projects at European University of Madrid in 2014. She is a researcher at Ohuchi architect and associates from 2012 and currently works at Nikken Sekkei LTD in Barcelona, Spain.

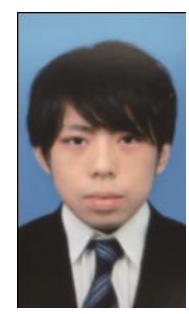

Kosuke Sato was born in Ibaraki, Japan in 1995. He received Bachelor of Engineering from Dept. of Architecture and Architectural Engineering, College of Industrial Technology, Nihon University, Chiba, Japan in 2018, he is a graduate student of Graduate School of Industrial Technology at Nihon University, Chiba, Japan.

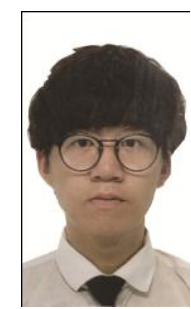

Zong Shichun was born in Tianjin, China in 1990. He received Bachelor of Engineering from Dept. of Architecture and Architectural Engineering, College of Industrial Technology, Nihon University, Chiba, Japan in 2016, and received Master of Engineering from at Graduate School of Industrial Technology at Nihon University, Chiba, Japan in 2018, he is currently enrolled in a doctoral course at Graduate School of Industrial Technology at Nihon University, Chiba, Japan.

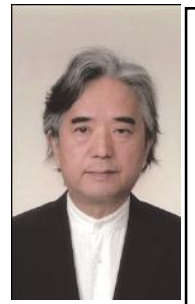

Hirotomo Ohuchi was born in Tokyo, Japan 1954. He received Doctor of Engineering from Nihon University. $\mathrm{He}$ is currently professor architect at Department of Architecture in Nihon University and the principal of Ohuchi architect and associates. He is a Japan registered architect and a member of Japan Institute of Architects and member of Architectural Institute of Japan. He has won many awards, notable among them being the Academy of France Architects Award in the International Architectural Design Competition for students from UIA (International Union of Architects) and The Poland Award in the International Urban Design Competition for Young Architects in 1990 from UIA (International Union of Architects). 